\title{
Development of Myocardial Contractile System in the Fetal Rabbit
}

\author{
TOSHIO NAKANISHI, HIROFUMI OKUDA, KIYOMI KAMATA, KAZUHIKO ABE, \\ MORIE SEKIGUCHI, AND ATSUYOSHI TAKAO \\ Department of Pediatric Cardiology and Department of Cardiology, Heart Institute of Japan, Tokyo Women's \\ College, Tokyo, Japan
}

\begin{abstract}
Developmental changes in the myocardial contractile system were evaluated in the fetus at 18, 21, and 28 days of gestation (full term 31 days) and in 3- to 5day-old newborn rabbits. Mechanical function was studied using the isolated arterially perfused heart. Perfusion with ryanodine $\left(10^{-5} \mathrm{M}\right)$, an inhibitor of $\mathrm{Ca}$ release from the sarcoplasmic reticulum, decreased contractile force and increased the time to peak tension in the 28-day fetus and newborn but these changes were minimal in the 18- and 21-day fetus. Postextrasystolic potentiation, which is thought to be caused by $\mathrm{Ca}$ release from the sarcoplasmic reticulum, was observed in the 28-day fetus and the newborn, but was not significant in the 18- and 21-day fetus. An ultrastructural study showed poorly developed sarcoplasmic reticulum and myofibrils in the 18- and 21-day fetus. Although the maximum developed tension observed at high extracellular calcium increased with development, the relative value of developed tension at various extracellular calcium was similar in the three fetal groups and only in the newborn the extracellular calcium-developed tension curve shifted to the right. Myofibrillar yield increased with development but sensitivity of myofibrillar ATPase activity to $\mathrm{Ca}$ was similar in the fetus and newborn. These data suggest that 1) the sarcoplasmic reticulum does not function significantly in the 18- and 21-day fetus, 2) although sarcoplasmic reticulum starts to function at late gestation, it does not cause significant changes in intracellular calcium in the fetal period, 3 ) myocardial contractility remains similar in the fetus from the 18th to 28 th day of gestation and major changes in contractility occur after birth. (Pediatr Res 22: 201-207, 1987)
\end{abstract}

Abbreviations
DT, developed tension
+dT/dt(max), maximal rate of tension development
TPT, time to peak tension
1/2RT, half relaxation time
PES, paired electric stimulation
RT, resting tension
[Ca]o, extracellular calcium

In the adult myocardium, a relatively small $\mathrm{Ca}$ influx across the sarcolemma induces the subsequent release of greater

Received November 3, 1986; accepted March 27, 1987.

Correspondence Toshio Nakanishi, M.D., Pediatric Cardiology, Heart Institute of Japan, Tokyo Women's Medical College, 10 Kawadacho, Shinjuku, Tokyo, Japan.

Supported by Research Grant 59480241 and 59570411 from the Japanese Ministry of Education, Science, and Culture and by a grant-in-aid from the Japan Research Promotion Society for Cardiovascular Diseases. amounts of $\mathrm{Ca}$ from the sarcoplasmic reticulum, which then activates the myofilaments (1). The study of Nakanishi and Jarmakani (2) suggests that the role of the sarcoplasmic reticulum in cardiac contraction in the newborn and near-term fetus is less than in the adult. Furthermore, several investigators (3-10) have shown that the neonatal myocardium develops less force than the adult myocardium and myofibrillar and sarcoplasmic reticulum contents increase with development. However, these studies were performed using neonatal or near-term fetal animals and contractile system in the early mammalian fetus has not been studied extensively. The purpose of the present study was to investigate developmental changes in the contractile system in the relatively early stages of the fetal rabbit and to examine when the sarcoplasmic reticulum starts to function.

\section{METHODS}

The experiments utilized the fetus at the 18th, 21st, and 28th day of gestation (term 31 days), and 3- to 5-day-old newborn New Zealand White rabbits. For technical reasons the earliest fetal stage we could examine was the 18th day of gestation. After the doe was killed by a sharp blow to the head, the fetuses were delivered by cesarian section and were used immediately. The fetal and newborn rabbits were killed by decapitation. The heart was then excised from the chest cavity and used for the ultrastructure study, biochemical determination, and mechanical function study.

Ultrastructure. Small pieces of the muscle were dissected out from the left ventricular free wall and placed in ice-cold $3 \%$ glutaraldehyde fixative buffered with $0.1 \mathrm{M}$ phosphate buffer (pH 7.4). Muscles were then quickly sliced lengthwise into thin strips and left in the fixative for $60 \mathrm{~min}$. After three washings with $0.1 \mathrm{M}$ phosphate buffer $(\mathrm{pH} 7.4)$, the muscles were placed in $\mathrm{OsO}_{4}(1 \%)$ buffered with $0.1 \mathrm{M}$ phosphate buffer. After osmication, the muscles were dehydrated in ethanol and embedded in a Poly Bed 812 resin. Thin sections for electron microscopy were cut with a glass knife on an ultramicrotome (LKB Ultrotome V) and stained with uranyl acetate and lead citrate. These sections were examined using a Nihondenshi (JEM1200EX) electron microscope at magnification of $\times 2,000$ and $\times 10,000$. Morphometric analysis was performed in three animals of a different litter for each age group. A total of 20 micrographs for each group was taken and cell diameters and the relative area occupied by the myofibrils and mitochondria in the cell (excluding the extracellular space) was measured using an electrical digitizer (Kontron). Since the present morphometric method did not measure the cellular and organelle volume, the present measurement should be considered as a semiquantification.

Biochemical study. Approximately 40 hearts from the 21-day fetus, four hearts from the 28-day fetus, and two hearts from newborn were used for each experiment for the isolation of 
myofibrils. All hearts had been frozen and stored in liquid nitrogen and myofibrils were isolated as described previously (2, 12). The 18-day fetus was not used for myofibrils isolation for technical reasons.

Myofibrillar ATPase activity was measured at $27^{\circ} \mathrm{C}$ and at low ionic strength $(0.0757 \mathrm{M})$. Low ionic strength was chosen to prevent myosin dissolution and myofibrillar ATPase under these conditions is considered to represent actin-activated myosin ATPase in the presence of troponin and tropomyosin (11). The reaction medium contained $30 \mathrm{mM}$ TES, $1 \mathrm{mM}$ EGTA, 3.58 $\mathrm{mM} \mathrm{Na}$-ATP, $6.8 \mathrm{mM} \mathrm{MgCl}_{2}, 5 \mathrm{mM}$ azide, $47 \mathrm{mM} \mathrm{KCl}$, and various amounts of $\mathrm{CaCl}_{2}(\mathrm{pH} 7.1$ with $\mathrm{KOH})$. A desired $\mathrm{Ca}$ concentration in the medium was obtained using an EGTA buffer system (2). The reaction was started by the addition of enzymes and stopped by the addition of $0.5 \mathrm{ml}$ of $20 \%$ trichloroacetic acid. Inorganic phosphate concentration in the medium was then measured using the method of Fiske and Subbarow (13). Protein was measured by the Lowry method (14) using bovine serum albumin as a standard.

The myofibrillar ATPase activity was determined at various Ca concentrations (from $10^{-8}$ to $10^{-5} \mathrm{M}$ ), and the sensitivity of myofibrillar ATPase to $\mathrm{Ca}$ was calculated as;

$$
\% \text { activation }=100 \times \frac{- \text { basal APTase }(\text { no Ca added })}{\text { maximal ATPase }- \text { basal ATPase }}
$$

In a preliminary study, effects of azide $(5 \mathrm{mM})$, ouabain $(5$ $\mathrm{mM})$, and quinidine $(1 \mathrm{mM})$ on myofibrillar ATPase were examined and results showed no significant effects, suggesting that mitochondrial, sarcolemmal, and sarcoplasmic reticulum contaminations in the myofibrillar fraction were minimal (15).

Mechanical function study. Perfusion Solution. The control Krebs-Henseleit solution contained in $\mathrm{mM}$ : $\mathrm{NaCl}, 118 ; \mathrm{KCl}, 6$; $\mathrm{CaCl}_{2}$, 1.5; glucose, 6; $\mathrm{MgCl}_{2}, 1 ; \mathrm{NaHCO}_{3}, 24 ; \mathrm{NaH}_{2} \mathrm{PO}_{3}, 0.436$. The control solution was equilibrated with $95 \% \mathrm{O}_{2}$ and $5 \% \mathrm{CO}_{2}$ yielding a final $\mathrm{pH}$ of 7.35-7.42.

The control HEPES solution contained (mM): $\mathrm{NaCl}, 133$; $\mathrm{KCl}, 6 ; \mathrm{CaCl}_{2}, 1.5 ; \mathrm{MgCl}_{2}, 1.0$; glucose, 6; HEPES, 3.0. This solution was bubbled with $100 \% \mathrm{O}_{2}$ and the $\mathrm{pH}$ was adjusted to 7.4 with $0.1 \mathrm{~N} \mathrm{NaOH}$. Lanthanum $\left(\mathrm{La}^{3+}, 5 \mu \mathrm{M}\right)$ was added to the control HEPES solution.

Experimental Preparation. Experiments were performed in the isolated, arterially perfused ventricular preparation as described previously $(2,16-20)$. The aorta was cannulated with a PE-50 polyethylene cannula and then perfused with oxygenated perfusate at a constant perfusion rate of $2.5 \mathrm{ml} / \mathrm{g}$ tissue per min using a Harvard pump. The base of the right and left ventricle was fixed between two Harmon forceps and the apex was attached to the Statham (UC3) force transducer using a silk suture. The muscle was stimulated at $40 \mathrm{bpm}$, and its temperature was maintained at $27 \pm 0.5^{\circ} \mathrm{C}$. The following parameters of mechanical function were monitored continuously: DT, RT, $+\mathrm{dT} / \mathrm{dt}$ max, TPT, and $1 / 2$ RT. TPT was defined as the time from the onset to the peak of developed tension, and $1 / 2 \mathrm{RT}$ as the time required for tension to fall to $50 \%$ of the maximal value. In isometric contraction, DT is largely dependent on the cytosolic Ca concentration and the amount of myofibrils. $+\mathrm{dT} / \mathrm{dt}(\max )$, on the other hand, is related to the maximal intensity of active state $(23,28)$, which in turn is mainly related to the rate of cytosolic Ca change.
In the present study a whole heart was suspended at three points and DT represents one of three force vectors. Because the muscle preparation was not cylindrical, parameters of mechanical function were normalized for the wet weight rather than for the cross-sectional area. Although the papillary muscle preparation may be more desirable for a mechanical function study, the whole heart preparation was used in the present study for two reasons: 1) technical limitations due to a small size of the fetal heart, and 2) in order to perform mechanical and biochemical studies in the same tissue. It must be noted, however, that although the heart weights changed with growth, the geometry of the preparation remained similar.

Experimental Protocol. Initially the muscles were perfused with a control solution containing $1.5 \mathrm{mM}$ calcium for $60 \mathrm{~min}$ to allow for stabilization of mechanical function. During the initial $40 \mathrm{~min}$ of each experiment, the length of the muscle preparation was adjusted so that the tension was equal to $90 \%$ of maximal tension. After this initial period, both resting tension and the length-tension relationship remained unchanged under control condition. The following studies were then performed.

Calcium and mechanical function. After stabilization of mechanical function, muscles were perfused with solutions containing $0.1,0.3,0.75,3.0,7.5,15$, and $30 \mathrm{mM} \mathrm{Ca}^{2+}(n=9$ in each age group). There was no visible precipitation in any of the solutions. The duration of perfusion was $15 \mathrm{~min}$ at each calcium concentration. Mechanical function reached a new steady state within $10 \mathrm{~min}$ after switching to a new concentration.

Paired electrical stimulation. The response to PES was studied by subjecting the muscles to a repetitive pattern of 10 paired stimuli ( $n=5$ in each age group). In a preliminary study, the intervals between the paired stimuli were progressively increased from 300 to $800 \mathrm{~ms}$ in increments of $50 \mathrm{~ms}$. The maximal inotropic effect of PES occurred when the interval between the paired stimuli was $500 \mathrm{~ms}$ and this interval was mainly used.

Ryanodine effect. We used ryanodine to determine the role of the sarcoplasmic reticulum in cardiac contraction. In a preliminary study, various concentrations of this drug (from $10^{-9}$ to $10^{-5} \mathrm{M}$ ) were used and the negative inotropic effect did not increase further at concentrations greater than $10^{-6} \mathrm{M}$. Muscles were perfused with a solution containing $10^{-5} \mathrm{M}$ ryanodine for $30 \min (n=5)$. Mechanical function reached a new steady state within $15 \mathrm{~min}$.

La effect. Because $\mathrm{La}^{3+}$ precipitates out of bicarbonate buffer solution, effect of $\mathrm{La}^{3+}$ on mechanical function was studied using the HEPES solution. After 60 -min stabilization of mechanical function with a control HEPES solution, the muscle was perfused for 40 min with a HEPES solution containing $5 \mu \mathrm{M} \mathrm{La}^{3+}(n=5$ in each age group).

Statistical analysis. Results were expressed as mean \pm SE. One-way analysis of variance was used for multigroup components. Statistical significance of difference between group means was determined using modified $t$ test (21). Percent changes were compared using nonparametric methods (Wilcoxon's rank sum test) (22). The probability was considered to be significant if the $p$ value was less than 0.05 .

\section{RESULTS}

Ultrastructure. From the 18th day of gestation to newborn, heart weight increased about 80 times (Table 1). Figures 1 and 2

Table 1. Heart and body wt (mean $\pm S E)$

\begin{tabular}{ccccc}
\hline Age & $n$ & Body wt $(\mathrm{g})$ & Heart wt $(\mathrm{g})$ & Heart wt/body wt $\times 100$ \\
\hline 18-day fetus & 8 & $1.25 \pm 0.05$ & $0.0043 \pm 0.0006$ & $0.34 \pm 0.03$ \\
21-day fetus & 8 & $2.9 \pm 0.06$ & $0.0132 \pm 0.005$ & $0.46 \pm 0.03$ \\
28-day fetus & 12 & $30 \pm 0.9$ & $0.136 \pm 0.005$ & $0.46 \pm 0.01$ \\
5-day newborn & 9 & $85 \pm 5$ & $0.34 \pm 0.09$ & $0.40 \pm 0.05$ \\
\hline
\end{tabular}


show electron micrographs of the left ventricle and Table 2 shows morphometric data. Although the present measurement was a semiquantification, the value was in agreement with the data of Page and Buecker (10), who measured the myofibrillar volume fraction in the newborn rabbit. There was no significant difference in the cellular diameter in the four age groups (Table 2). In the newborn, myofibrils were well organized and loose networks of the sarcoplasmic reticulum were also observed (Fig. 1). In the 28-day fetus, myofibrillar and sarcoplasmic reticulum concentrations were less than in the newborn. In the 21- and 18-day fetuses, intracellular organelles were packed more loosely; myo-

Table 2. Morphometric data (mean \pm SE of 20 measurements)*

\begin{tabular}{lccc}
\hline & \begin{tabular}{c} 
Cell \\
diameter \\
\cline { 3 - 4 } \multicolumn{1}{c}{ Group }
\end{tabular} & \multicolumn{2}{c}{ Organelle fractions (\%) } \\
\cline { 3 - 4 } 18-day fetus & $5.3 \pm 0.3$ & Myofibrils & Mitochondria \\
21-day fetus & $5.5 \pm 0.5$ & $13.0 \pm 1.7$ & $7.3 \pm 1.8$ \\
28-day fetus & $4.9 \pm 0.5$ & $24.3 \pm 2.1 \dagger$ & $17.3 \pm 1.3$ \\
Newborn & $6.8 \pm 0.9$ & $39.0 \pm 2.5 \ddagger$ & $15.3 \pm 1.5 \dagger$ \\
\hline
\end{tabular}

* The organelle fraction was determined by measuring the relative area occupied by the organelle in the cytoplasm.

$\dagger$ Significantly $(p<0.05)$ different from the 18- and 21-day fetal values.

$\ddagger$ Significantly $(p<0.05)$ different from the 18-, 21-, and 28-day fetal values. fibrils were scarce and disorganized and the sarcoplasmic reticulum was very scarce and observed only occasionally (Fig. 2).

Myofibrillar content and ATPase activity. In agreement with the ultrastructure data, the yield of myofibrils in the 21-day fetus $(8.3 \pm 1.8 \mathrm{mg} / \mathrm{g}$ muscle) was significantly less than in the 28-day fetus $(16 \pm 1)$ and newborn $(30 \pm 3)$. Maximal ATPase activity was observed at pCa 6 and 5 in all age groups and the newborn value was significantly greater than the fetal values (no difference between the 21 - and the 28 -day fetus) (Fig. $3 A$ ). Figure $3 B$ shows Ca-activated ATPase activity expressed as percent of the maximal value. There was no difference in the relative value of the $\mathrm{Ca}$ ATPase activity.

Mechanical function. Mechanical function data under control conditons are shown in Table 3. RT decreased and DT and $+\mathrm{dT} / \mathrm{dt}(\max )$ increased with development, but TPT and 1/2RT did not change significantly with development.

Response to Calcium. The effect of high $[\mathrm{Ca}]_{0}$ on DT and $+\mathrm{dT} / \mathrm{dt}(\max )$ was similar but since DT is considered to be related to the amount of myofibrils more directly (23), DT data are shown (Fig. 4). The greatest DT observed in each age group at high $[\mathrm{Ca}]_{0}$ increased with development (Fig. $4 A$ ).

The relative value of DT at various $[\mathrm{Ca}]_{0}$ in each group is shown in Figure $4 B$. The dependency of DT to $[\mathrm{Ca}]_{0}$ in the three fetal groups was similar but the newborn curve shifted to the right. DT reached one-half maximal value $(\mathrm{Km})$ at $0.98 \pm 0.15$ $\mathrm{mM}[\mathrm{Ca}]_{0}$ in the 18 -day fetus, $0.99 \pm 0.24$ in the 21 -day fetus, $0.99 \pm 0.12$ in the 28 -day fetus, and $2.0 \pm 0.17$ in the newborn. The newborn value was significantly greater than the fetal values.
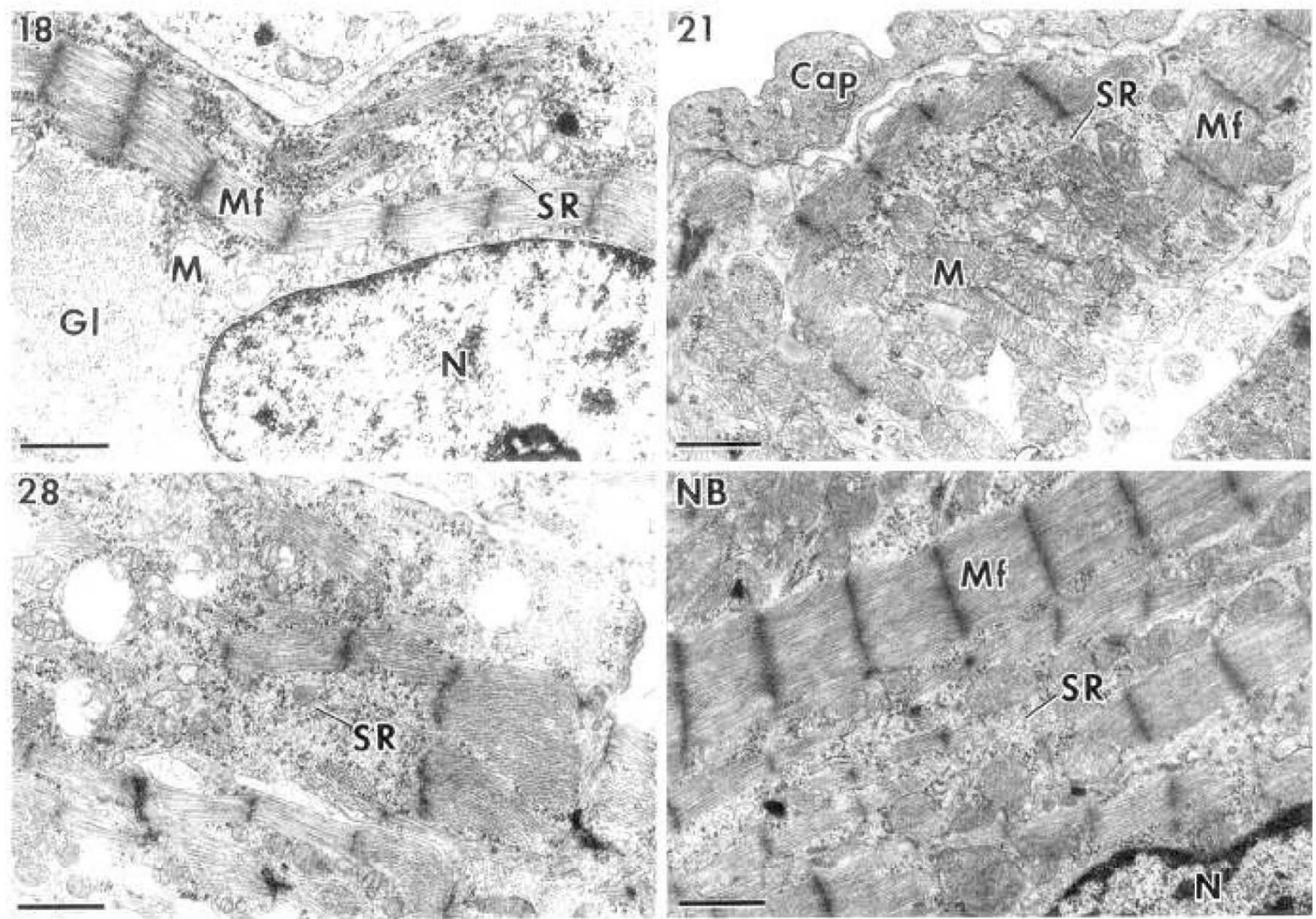

Fig. 1. Low magnification of electron micrographs of the left ventricle. From the 18-day fetus to the newborn, the amount of myofibrils increased with development. 18 , the 18-day fetus; 21 , the 21-day fetus; 28 , the 28-day fetus; $N B$, newborn; $G l$, glycogen granules; $M f$, myofibrils; $M$, mitochondria; $N$, nucleus; $S R$; sarcoplasmic reticulum. Calibration bars are $1 \mu \mathrm{m}$. 

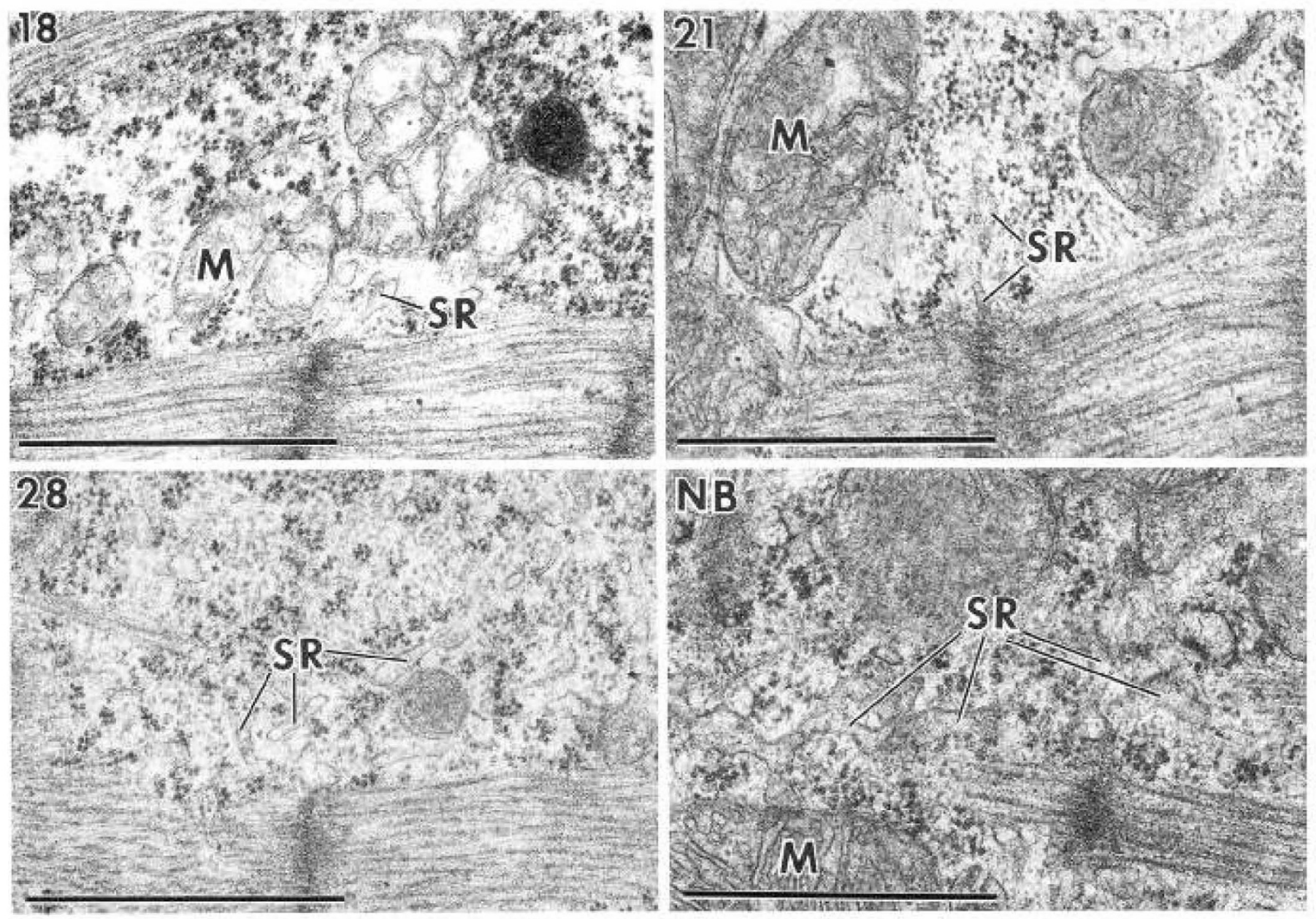

Fig. 2. Medium magnification electron micrographs of the left ventricle. Loose network of the sarcoplasmic reticulum is observed in the newborn. In the 18-and 21-day fetus the sarcoplasmic reticulum was very scarce. Calibration bars are $1 \mu \mathrm{m}$.

Reviewing Figure $3 B$ and $B$ suggests that in the newborn intracellular $\mathrm{Ca}$ concentration, rather than the Ca sensitivity of myofibrils, is different from that in the fetus.

At $30 \mathrm{mM}[\mathrm{Ca}]_{0}, 1 / 2 \mathrm{RT}$ increased significantly in the four age groups (to $122 \pm 4 \%$ of control in the newborn, $132 \pm 5 \%$ in the 28-day fetus, $142 \pm 2 \%$ in the 21 -day fetus, and $151 \pm 3 \%$ in the 18-day fetus). The increase in the 21- and 18-day fetus was significantly greater than in the newborn.

Paired Electrical Stimulation. Sarcoplasmic reticulum plays an important role in the regulation of intracellular $\mathrm{Ca}$ (2). Previous studies suggested that the inotropy of PES results from $\mathrm{Ca}$ release from intracellular sites including the sarcoplasmic reticulum and $T$ tubular system (6). Therefore, to determine developmental changes in Ca release from the sarcoplasmic reticulum, effect of PES was studied. PES increased both DT and $+\mathrm{dT} /$ $\mathrm{dt}(\max )$ similarly and only $+\mathrm{dT} / \mathrm{dt}$ data are shown in Figure 5. There was no significant inotropic effect of PES in the 18- and 21-day fetus. Significant inotropy was observed in the 28-day fetus but it was less than in the newborn (Fig. 5).

Ryanodine Effect. Ryanodine selectively inhibits Ca uptake and release from sarcoplasmic reticulum $(24,25)$. In the newborn ryanodine $\left(10^{-5} \mathrm{M}\right)$ significantly increased TPT and decreased the rate of tension development. Alteration of DT after ryanodine infusion was less than that of $+\mathrm{dT} / \mathrm{dt}(\max )$ (Fig. 6). TPT was not altered significantly by this drug in the 18- and 21-day fetus. A negative inotropic effect was observed in all age groups, but that was minimal in the 18- and 21-day fetus. Changes in TPT and $+\mathrm{dT} / \mathrm{dt}(\max )$ in the 28-day fetus was greater than in the 18- and 21-day fetus but less than in the newborn (Fig. 7).
$\mathrm{La}^{3+}$ Effect. To evaluate developmental changes in the role of the sarcolemma in excitation-contraction coupling, the muscle was perfused with a solution containing $\mathrm{La}^{3+}$. $\mathrm{La}^{3+}$ displaces $\mathrm{Ca}$ bound to the sarcolemma and blocks sarcolemmal Ca influx, but it does not permeate the plasma membrane (26). $\mathrm{La}^{3+}$ caused a rapid decrease in DT and $+\mathrm{dT} / \mathrm{dt}(\max )$ and the mechanical function reached a new steady state within $30 \mathrm{~min}$. $\mathrm{La}^{3+}$ caused a severe decline in $+\mathrm{dT} / \mathrm{dt}(\max )$ in the 18- and 21 -day fetus (Fig. 8). The La-induced decrease in $+\mathrm{dT} / \mathrm{dt}(\max )$ in the 28-day fetus was greater than in the newborn but less than in the 18- and 21day fetus.

\section{DISCUSSION}

According to the data of Sissman (27), cardiovascular anatomy is established in the rabbit by approximately the 16th day of gestation. Therefore, the present study examined the fetal heart function after the gross formation of the heart was complete.

Contractile force is largely determined by the amount of contractile protein (and its ATPase activity) and the amount of calcium reaching the myofilaments. In the present study, the maximal DT and $+\mathrm{dT} / \mathrm{dt}(\max )$ that were observed in each age group at high $[\mathrm{Ca}]_{0}$ increased with age (Fig. $4 A$ ). These data suggest that not only myocardial force but also "contractile reserve" increase with development. Because DT reached a plateau at high $[\mathrm{Ca}]_{0}$, it is likely that the myofilaments were saturated with calcium under these conditions (2). Therefore, the differences in maximal DT at high $[\mathrm{Ca}]_{0}$ are most likely due to the differences in the amount of contractile protein. In the present 
study, ultrastructure showed decreased myofibrillar fraction in the early fetus. It may be argued that tissue fixation, dehydration, and embedding procedures affect the ultrastructural data. However, there was no indication of organelle swelling in any age groups in the present study. Furthermore, myofibrillar yield determined by the biochemical study in the 21-day fetus was less than in the newborn. These data suggest that decreased myofibrillar content is the main reason for the low contractile force in the fetus.

Nakanishi and Jarmakani (2) showed previously that the de-
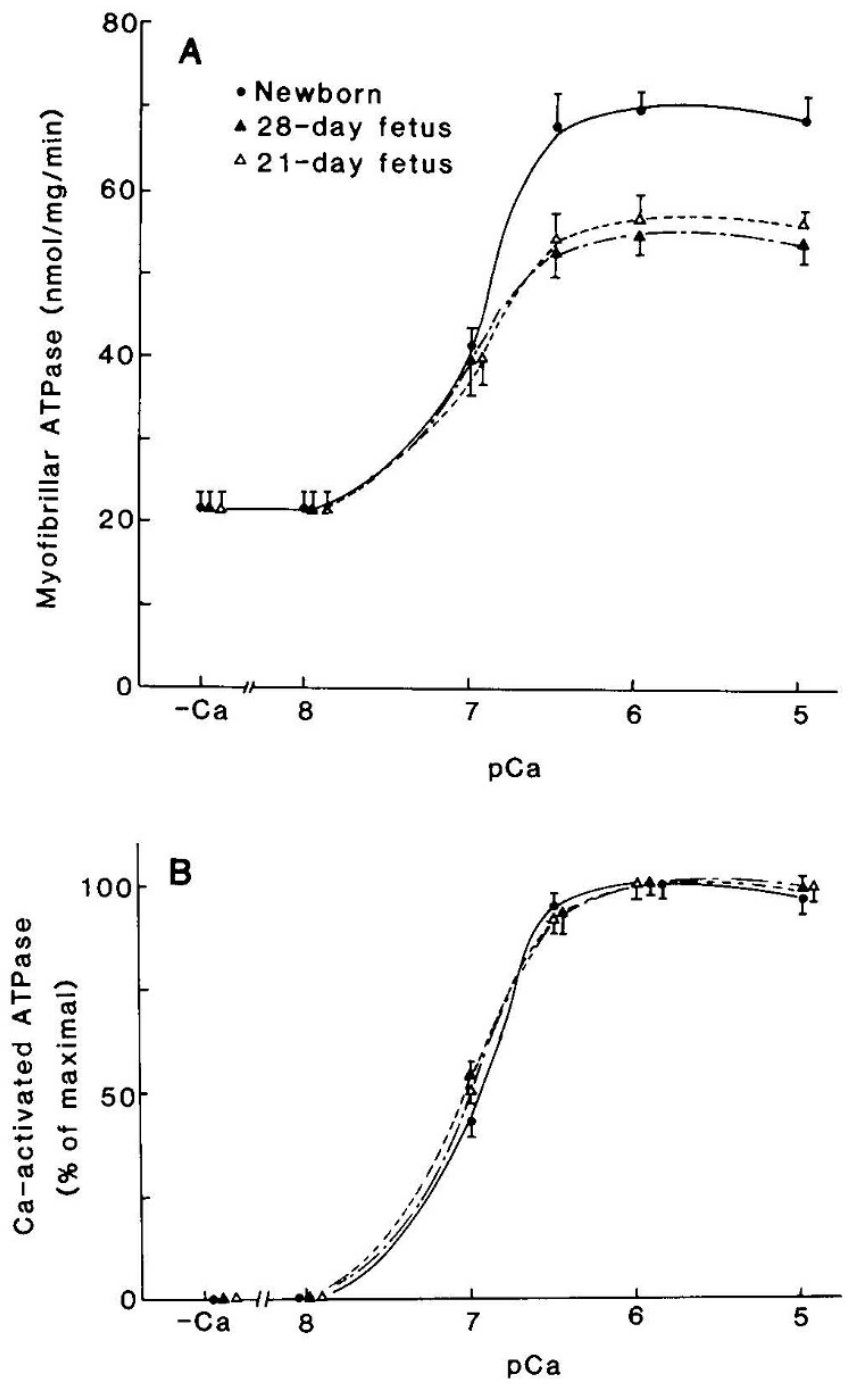

Fig. 3. Myofibrillar ATPase activity as a function of $\mathrm{pCa}(-\log [\mathrm{Ca}])$. Myofibrillar ATPase activity expressed as $\mathrm{nmol} / \mathrm{mg} / \mathrm{min}$ in the 21 - and 28-day fetus was less than in the newborn $(A)$, but Ca-activated ATPase expressed as percent of the maximal value was similar in the three age groups $(B)$. pendency of DT on [Ca $]_{0}$ in the 28-day fetus was similar to that in the adult but different from that in the newborn. The present study showed that the dependency of DT on $[\mathrm{Ca}]_{0}$ does not change significantly during the fetal period from the 18 th to the 28th day. Since sensitivity of myofibrillar ATPase to $\mathrm{Ca}$ was similar, it is likely that in the newborn the effect of $[\mathrm{Ca}]_{0}$ on intracellular $\mathrm{Ca}$ concentrations is different from that in the fetus.

The regulatory mechanism of intracellular calcium concentration is complex but we speculated previously that development of the sarcoplasmic reticulum has an important effect on $[\mathrm{Ca}]_{i}$ (2). Postextrasystolic potentiation was examined because previous studies suggest that the inotropy of PES results from $\mathrm{Ca}$ release from the sarcoplasmic reticulum (6). In the present study, there was no inotropic effect of PES in the 18-and 21-day fetus. This suggests that the sarcoplasmic reticulum may not be functioning significantly at these stages. The data obtained using ryanodine (a selective inhibitor of $\mathrm{Ca}$ release from the sarcoplasmic reticulum) $(21,22)$ are also in agreement with the PES data. Furthermore, the ultrastructural study confirmed the poor development of the sarcoplasmic reticulum in the early fetus.

$\mathrm{La}^{3+}$ was used as a sarcolemmal $\mathrm{Ca}$ blocker and the data suggest that in the 18- and 21-day fetal hearts most contractile $\mathrm{Ca}$ comes in across the sarcolemma. This is in agreement with the hypothesis that the role of sarcoplasmic reticulum is minimal in the early fetus.

The difference between the newborn and fetal hearts is shown schematically in Figure 9. From our previous study (2) and the present data, we conclude that contractile system develops from the early fetal type (Fig. $9 A$ ) to the newborn type (Fig. 9B), and then to the adult type (less $\mathrm{Ca}$ influx across the sarcolemma and more $\mathrm{Ca}$ release from the sarcoplasmic reticulum than in Fig. $9 B)$. Reviewing Figure $3 B$ and Figure $4 B$ suggests that in the fetus intracellular $\mathrm{Ca}$ concentration is higher than in the newborn. The precise reasons for this remain unclear but the decreased $\mathrm{Ca}$-sequestration by the sarcoplasmic reticulum may result in the increased cytosolic $\mathrm{Ca}$ in the fetus.

In the present study, although control value of relaxation parameter $(1 / 2 R T)$ in the four age groups was not different (Table $3), 1 / 2 \mathrm{RT}$ at high $[\mathrm{Ca}]_{0}$ in the fetus was greater than in the newborn. This suggests that the capability of Ca-sequestering system in the fetus is less than in the newborn.

The data shown in Figures 5 and 7 suggest that the functional role of the sarcoplasmic reticulum in the 28-day fetus is greater than in the 18-and 21-day fetus. Nevertheless, the dose response curve in Figure $4 B$ did not change in the fetal period. The reason for this is not clear but there may be several explanations: 1) development of sarcoplasmic reticulum in the 28-day fetus is not enough to cause any changes in the $[\mathrm{Ca}]_{0}-\mathrm{DT}$ curve, 2 ) sarcolemmal function may compensate the underdevelopment of the sarcoplasmic reticulum in the 18- and 21-day fetus so that the intracellular $\mathrm{Ca}$ concentration is maintained constant in the fetal period. To determine the precise reasons, further studies must be performed to measure Ca flux across the sarcolemma. The present data, however, do suggest that although sarcoplasmic reticulum appears to start functioning by the 28th day of gestation, cardiac contractility, as expressed in Figure $4 B$, does not change significantly during the fetal period from the 18 - to the 28-day of gestation.

Table 3. Baseline mechanical function (mean $\pm S E$ )

\begin{tabular}{|c|c|c|c|c|c|c|}
\hline Age & $n$ & $\begin{array}{c}\text { RT } \\
(\mathrm{g} / \mathrm{g})\end{array}$ & $\begin{array}{c}\text { DT } \\
(\mathrm{g} / \mathrm{g})\end{array}$ & $\begin{array}{c}+\mathrm{dT} / \mathrm{dt}(\max ) \\
(\mathrm{g} / \mathrm{s} / \mathrm{g})\end{array}$ & $\begin{array}{l}\text { TPT } \\
(\mathrm{ms})\end{array}$ & $\begin{array}{c}1 / 2 \mathrm{RT} \\
(\mathrm{ms})\end{array}$ \\
\hline 18-day fetus & 18 & $8.4 \pm 0.3^{*}$ & $3.1 \pm 0.9^{*}$ & $11.9 \pm 2.2^{*}$ & $392 \pm 10$ & $190 \pm 6$ \\
\hline 21-day fetus & 18 & $5.4 \pm 0.5$ & $4.6 \pm 0.9$ & $13.8 \pm 2.3^{*}$ & $407 \pm 15$ & $175 \pm 17$ \\
\hline 28-day fetus & 25 & $4.0 \pm 0.8$ & $6.1 \pm 0.8$ & $27.4 \pm 6.4$ & $377 \pm 11$ & $209 \pm 8$ \\
\hline 5-day newborn & 25 & $3.9 \pm 0.5$ & $6.8 \pm 0.5$ & $28.1 \pm 3.6$ & $380 \pm 17$ & $216 \pm 10$ \\
\hline
\end{tabular}

* Significantly $(p<0.05)$ different from the newborn value. 

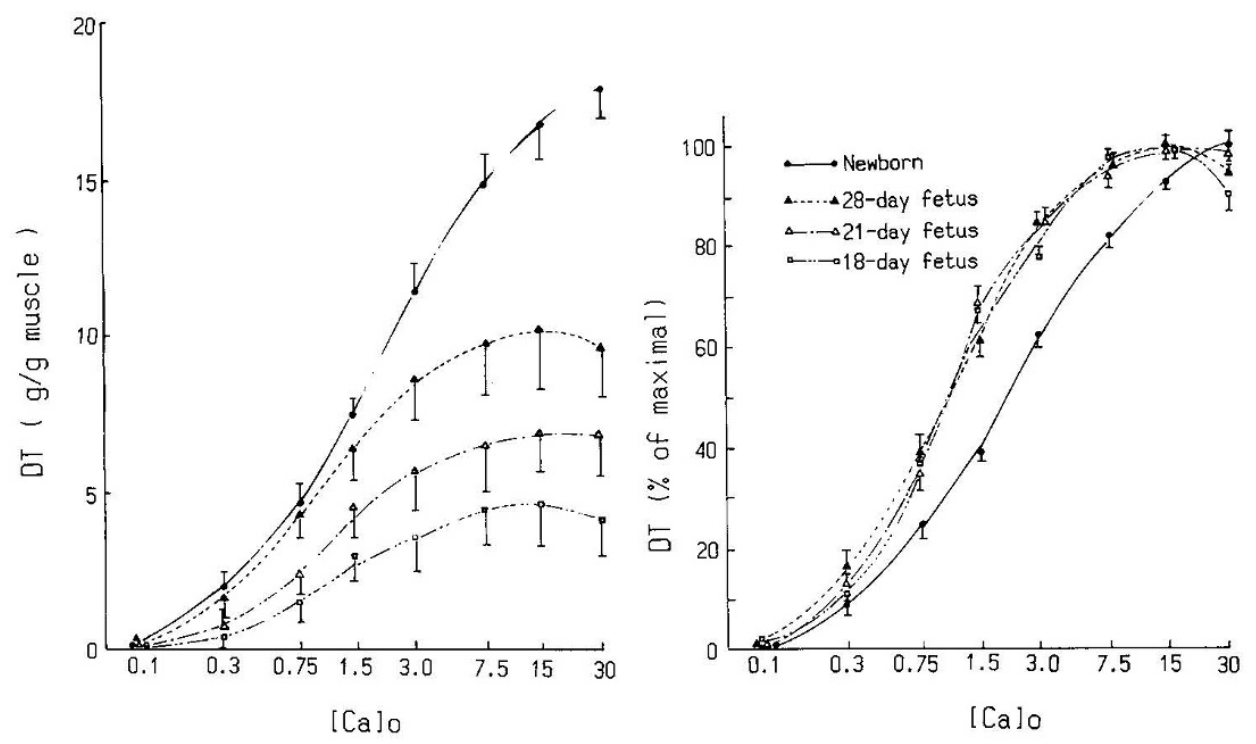

Fig. 4. Effect of extracellular calcium on DT. DT is expressed as $\mathrm{g} / \mathrm{g}$ muscle (left) and as a percentage of maximal values (right). Dependency of DT on $[\mathrm{Ca}]_{0}$ in the three fetal groups were similar but the newborn curve shifted to the right.

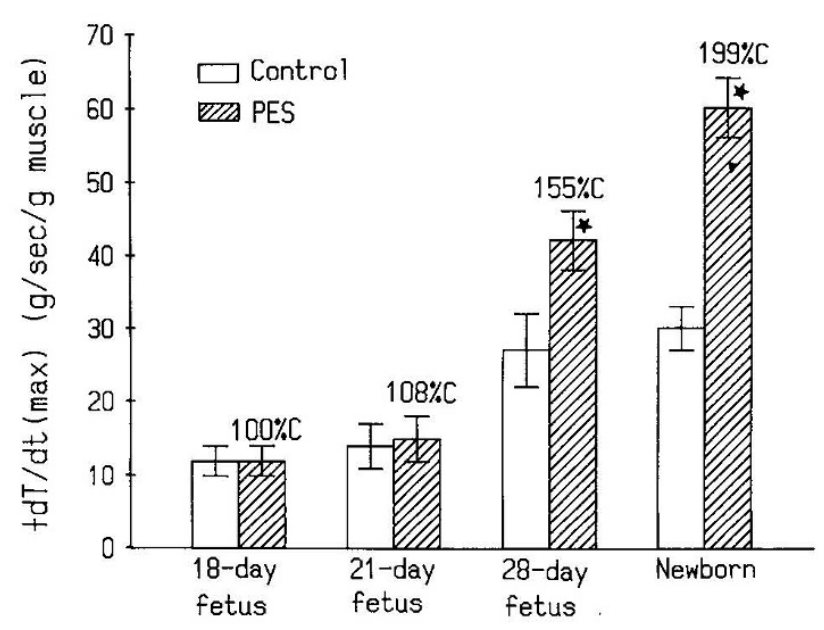

Fig. 5. Effect of paired electrical stimulation on the rate of tension development $(+d T / d t)$. There was no significant inotropic effect in the 18 - and 21-day fetus. $\star$ significant $(p<0.05)$ difference between control and PES.

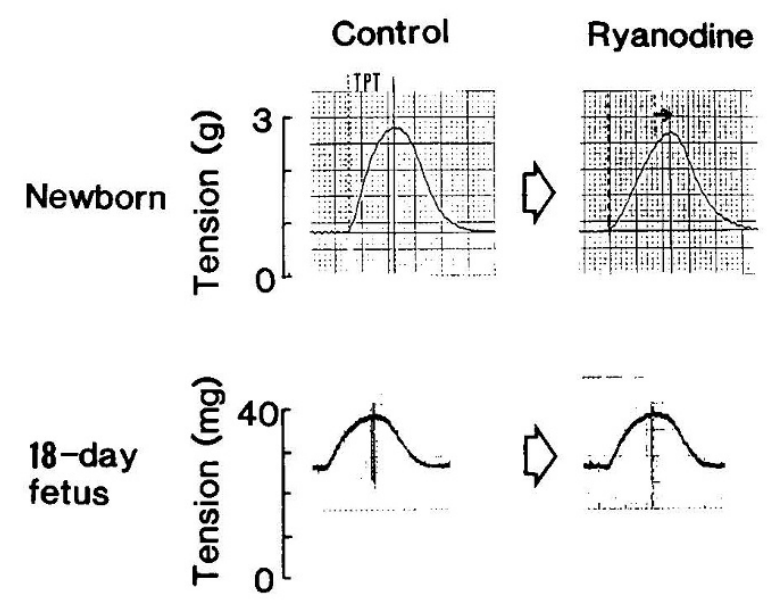

Fig. 6. Typical experiments that show effect of ryanodine. After ryanodine infusion, TPT increased in the newborn (solid arrow) but not in the 18-day fetus.

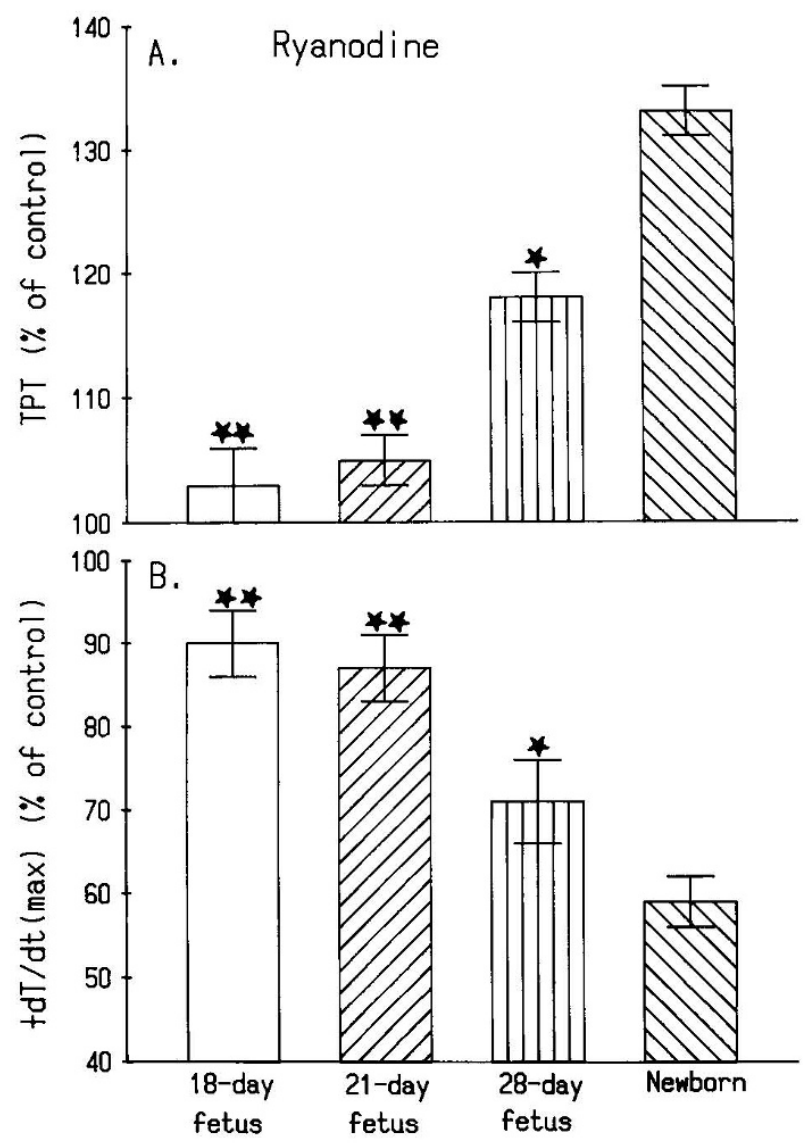

Fig. 7. Effect of ryanodine on the TPT and $+\mathrm{dT} / \mathrm{dt}(\mathrm{max})$. The effect of this drug in the 18- and 21-day fetus was minimal. $\star \star$ significantly different from the values in the 28 -day fetus and newborn. $\star$ significantly different from the values in the 18-day fetus, 21-day fetus, and newborn.

In summary, the present data show that the sarcoplasmic reticulum is underdeveloped and its function is minimal in the 18- and 21-day fetus. Although the sarcoplasmic reticulum starts to function at late gestation, development of this organelle causes major changes in contractility after birth. 


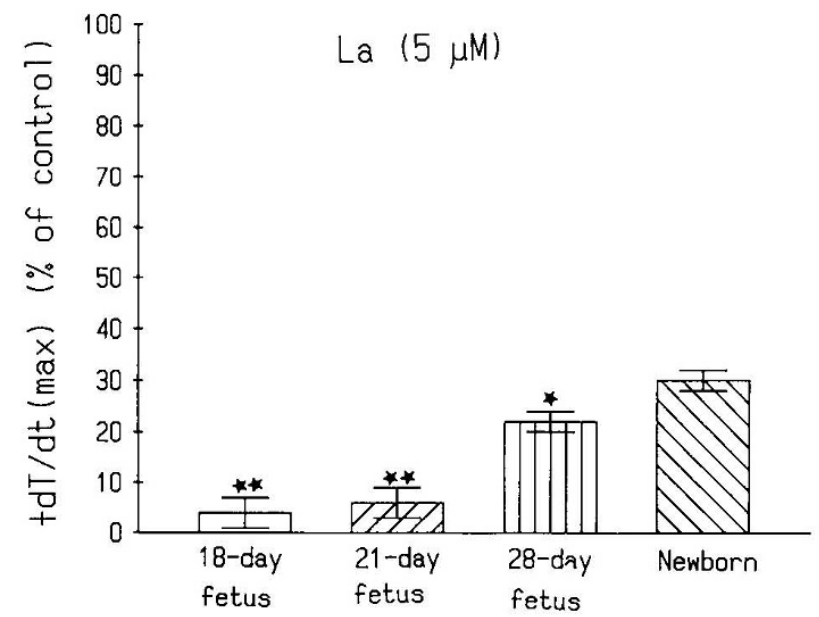

Fig. 8. Effect of lanthanum on $+\mathrm{dT} / \mathrm{dt}(\max )$. The negative inotropic effect of $\mathrm{La}$ in the 18-and 21-day fetus was significantly greater than in the 28-day and newborn. $\star \star$ significantly different from the values in the 28 -day fetus and newborn. $\star$ significantly different from the values in the 18-day fetus, 21-day fetus, and newborn.
A.

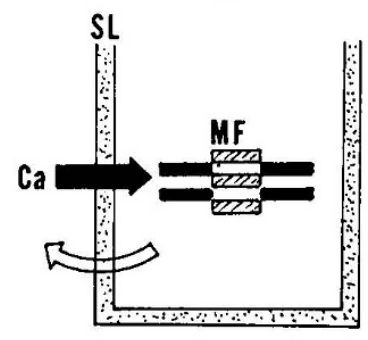

B.

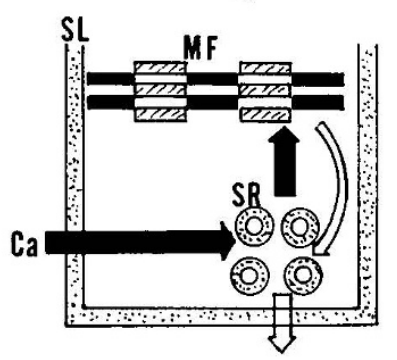

Fig. 9. Schematic diagrams showing developmental changes in the exitation-contraction coupling. The arrows represent $\mathrm{Ca}$ ion movements. In the early fetus $(A), \mathrm{Ca}$ entering the cell across the sarcolemma $(S L)$ directly reaches the myofilaments $(M F)$. In the newborn $(B), \mathrm{Ca}$ influx across the sarcolemma induces $\mathrm{Ca}$ release from the sarcoplasmic reticu$\operatorname{lum}(S R)$, which then activates the myofilaments.

\section{REFERENCES}

1. Fabiato A, Fabiato F 1978 Calcium induced release of calcium from the sarcoplasmic reticulum of skinned cells from adult human, dog, cat, rabbit, rat, and frog hearts and from fetal and newborn rat ventricles. Ann NY Acad Sci 307:491-522
2. Nakanishi T, Jarmakani JM 1984 Developmental changes in myocardial function and subcellular organelles. Am J Physiol 246:H615-625

3. Davies P, Dewar J, Tynan M, Ward R 1975 Postnatal changes in the lengthtension relationship of cat papillary muscles. J Physiol 253:95-102

4. Friedman WF 1972 The intrinsic physiologic properties of the developing heart. Prog Cardiovasc Dis 15:87-111

5. Hopkins SF, McCuthcheon EP, Wekstein DR 1973 Postnatal changes in rat ventricular function. Circ Res 32:685-691

6. Maylie JG 1982 Excitation-contraction coupling in neonatal and adult myocardium of cat. Am J Physiol 242:H834-843

7. Olivetti G, Anversa P, Loud A 1980 Morphometric study of early postnatal development in the left and right ventricular myocardium of the rat. Circ Res 46:503-512

8. Park I, Michael LH, Driscoll DJ 1982 Comparative response of the developing canine myocardium to inotropic agents. Am J Physiol 242:H13-18

9. Park MK, Sheridan PH, Morgan WW, Beck N 1980 Comparative inotropic response of newborn and adult rabbit papillary muscle to isoproterenol and calcium. Dev Pharmacol Ther 1:70-82

10. Page E, Buecker JL 1981 Development of dyadic junctional complexes between sarcoplasmic reticulum and plasmalemma in rabbit left ventricular myocardial cell. Circ Res 48:519-522

11. Scheuer J, Bhan AK 1979 Cardiac contractile protein. Circ Res 45:1-12

12. Nakanishi T, Nagae M, Takao A 1986 Developmental changes in contractile protein ATPase in the rabbit heart. Circ Res 58:890-895

13. Fiske $\mathrm{CH}$, Subbarow Y 1925 The colorimetric determination of phosphorus. J Biol Chem 66:375-400

14. Lowry OH, Rosebrough NJ, Farr AL, Randall RJ 1951 Protein measurements in the Folin phenol reagents. J Biol Chem 193:265-275

15. Soralo RJ, Pang DC, Briggs FN 1971 The purification of cardiac myofibrils with Triton x-100. Biochim Biophys Acta 245:259-262

16. Nakanishi T, Jarmakani JM 1981 The effect of acetyl strophanthidin on myocardial function and potassium and calcium exchange in the newborn rabbit. Am J Physiol 241:H637-H645

17. Nakanishi T, Matuoka S, Uemura S, Shimizu T, Nishioka K, Neufeld ND, Jarmakani JM 1984 Myocardial excitation-contraction coupling in the fetus of alloxan-diabetic rabbit. Pediatr Res 18:1344-1349

18. Nakanishi T, Shimizu T, Uemura S, Jarmakani JM 1984 Ouabain effect on myocardial mechanical function and sodium pump in the fetus. Am J Physiol 246:H213-H221

19. Nakanishi T, Okuda H, Nakazawa M, Takao A 1985 Effect of acidosis on contractile function in the newborn rabbit heart. Pediatr Res 19:482-488

20. Okuda H, Nakanishi T, Nakazawa M, Takao A 1987 Effect of isoproterenol on myocardial mechanical function and cyclic AMP content in the fetal rabbit. J Mol Cell Cardiol 19:151-157

21. Wallenstein S, Zucker CL, Fleiss JL 1980 Some statistical methods useful in circulation research. Circ Res 27:1-9

22. Snedecor GW, Cochran WG 1970 Statistical Methods. Iowa State University Press, Ames, IA

23. Koch-Weser J 1963 Effect of changes on strength and time course of contraction of papillary muscle. Am J Physiol 204:451-457

24. Sutko J, Willerson JT 1980 Ryanodine alteration of the contractile state of rat ventricular myocardium. Circ Res 46:332-343

25. Marban E, Wier WG 1985 Ryanodine as a tool to determine the contributions of calcium transient and contraction of cardiac Purkinje fibers. Circ Res $56: 133-138$

26. Bers DM, Langer GA 1979 Uncoupling cation effects on cardiac contractility and sarcolemmal Ca binding. Am J Physiol 237:H332-H341

27. Sissman NJ 1970 Developmental landmarks in cardiac morphogenesis. Am J Cardiol 25:141-147

28. Sonnenblick EH, Parmley WW 1967 Active state in heart muscle. In: Factors Influencing Myocardial Contractility. Academic Press, New York, pp 65-83 